\title{
Improvement Method Optimization of Automobile Warranty Quality Issue
}

\author{
Hongliang Du${ }^{1}$, Junyi $\mathrm{Lv}^{2}$, Zikun $\mathrm{Ye}^{1}$ and Rui Miao ${ }^{1 *}$ \\ ${ }^{1}$ School of Mechanical Engineering, Shanghai Jiao tong University, Shanghai, 200240, China \\ ${ }^{2}$ Baosteel-NSC Automotive Steel Sheets Co.,Ltd.,Shanghai,200941, China \\ *Corresponding author
}

\begin{abstract}
Automotive warranty quality issues from all aspects of quality control. In this paper, through the analysis of the existing automobile warranty problem solving process and the status of project quality management, combined with the current warranty quality problem solving challenges, expounds the current lack of warranty quality improvement and project quality management, and put forward the optimization scheme to improve the management, to show the anticipated improvement effect.
\end{abstract}

Keywords-warranty quality improvement method; project quality management

\section{INTRODUCTION}

Vehicle is a very high degree of integration of the product. The quality control of automobile is affected by the development, manufacturing, logistics, maintenance and other aspects of quality control of the vehicle and its parts. At the same time, as a popular means of transportation, the automobile has a very important significance to the national economy and the people's production and life.

The difficulty and importance of quality control exist at the same time, it requires automobile production enterprises must have perfect quality control system and method, to ensure that the car in the design, manufacturing, logistics and quality in all aspects of sales, to ensure the high quality of the products delivered to the user.

With the growing maturity and saturation of the automotive industry, the focus of competition has gradually shifted to the quality and customer loyalty. In addition, in recent years, the frequent emergence of vehicle recall, let us realize the importance of ensuring stable and superior product quality. Quality management work is not only able to provide high-quality products for the market to provide high quality products, but also in the long-term perspective, the enterprise can establish a superior brand image to make contributions.

Among the many factors affecting the quality of automobile, the quality of the design and development of the automobile project is the most obvious. Compared with the cost of quality improvement of the vehicle after the regular production, the cost of quality improvement in the early stage of the vehicle is much lower. Therefore, the domestic automobile enterprises gradually realize the importance of quality management in the early stage of automobile project quality management, and began to study the corresponding project quality control system and method according to its own characteristics.

In this paper, according to the existing warranty quality improvement work research, combined with the relevant data analysis, put forward the project prophase quality control and warranty quality management optimization program, for reference.

\section{ANALYSIS ON THE PRESENT AUtOMOBILE WARRANTY QUALITY IMPROVEMENT}

\section{A. Analysis on the Rootcause of Automobile Warranty Quality}

According to the automotive warranty-market quality issues to classify, resulting in complaints and claims the main reasons for the following categories:

Quality problems in engineering design, quality control of supplier quality problems, quality problems of vehicle manufacturing.

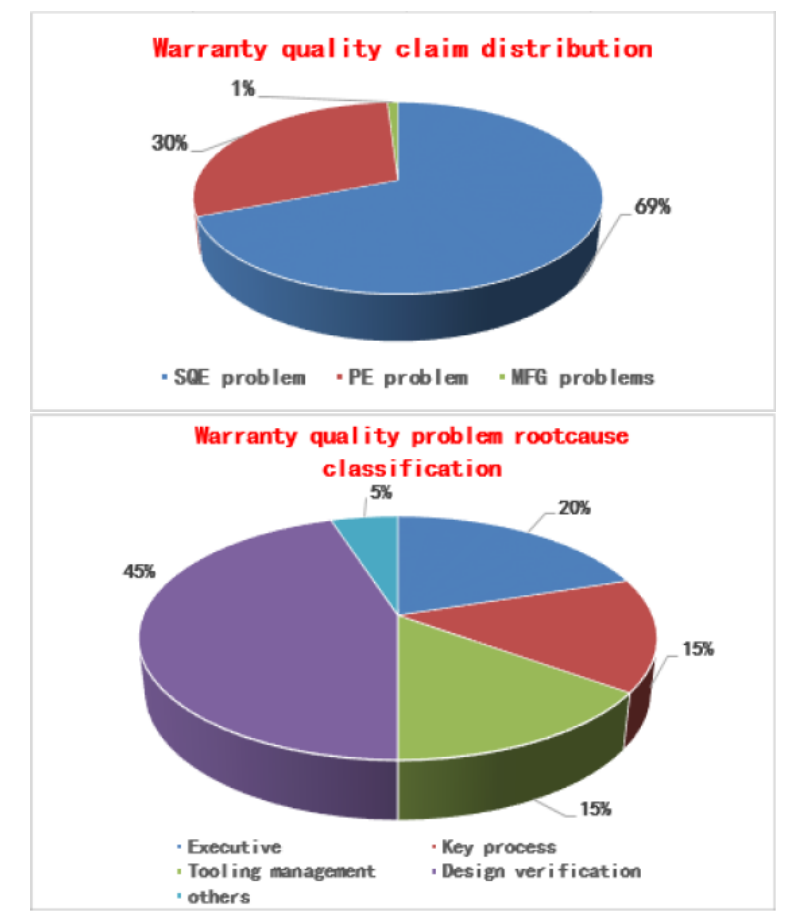

FIGURE I. MAJOR CATEGORIES OF REASONS FOR COMPLAINTS 
General vehicle companies will also be the supplier of black box parts design issues, classified into engineering design issues. Therefore, from the distribution of the causes of the problem can be seen in the data (Figure 1), the engineering design of the issue of quality problems accounted for more than $61 \%(30 \%+69 \% * 45 \%)$, the greatest impact on the post sales.

Usually, the root cause of the inflow of these engineering design problems to the end customer is the project phase of the prevention and validation is not sufficient. Therefore, the improvement of the project management process and methods of prevention and verification, improve the effectiveness of project issues to prevent and verify, is the key point to improve the performance of warranty quality.

\section{B. Automobile Warranty Quality Problem Solving Process}

Warranty quality problems in the current process of solving problem is: from the input to solve the problem, until the problem is closed, is concerned with the process of solving each problem, did not reflect the lessons learned and prevention of these problems.

Therefore, to some extent, the current vehicle warranty quality problem solving process has its limitations.

\section{Problems Faced by the Current Automobile Warranty Quality Improvement}

With the rapid development of the auto industry in recent years, the market models and car ownership is almost a geometric progression, the annual delivery of the customer's vehicles will reach ten million. Therefore, the improvement of automotive aftermarket quality problems facing the enormous pressure from the scale of the car. At the same time, in recent years, the network, WeChat and other new media, the growing popularity of instant communication, the requirements of the warranty quality response is also getting higher and higher.

With the national car "Three Guarantees" regulations promulgated, the vast majority of vehicle quality warranty extended, the national and social requirements for product quality has been further improved. This means that the improvement of the wattanty quality and response to the human, material and financial resources, the input requirements are getting higher and higher. Problem occurred after the passive response and resolve, has been unable to fundamentally improve customer satisfaction with product quality. Therefore, the traditional automobile warranty quality improvement efficiency and results, is facing more and more challenges, change the current automobile warranty quality improvement ideas and methods is imperative.

\section{CurRent Vehicle Product Project Quality CONTROL PROGRAM}

\section{A. General Development Process of Automotive Products}

Automotive products from the project to the vehicle production, according to GM's global development process (GVDP), mainly divided into the following stages: architecture development, design, engineering development, test mold development, production launch, the above process, as shown in Figure II:

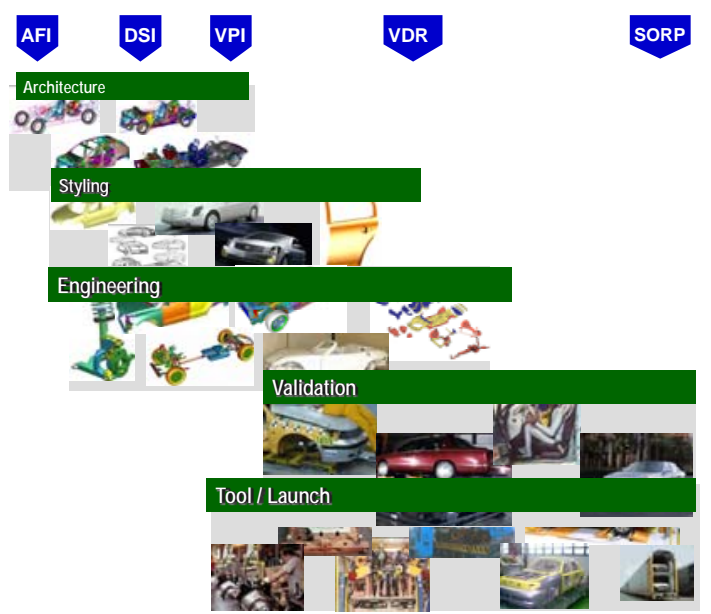

FIGURE II. DIVIDED STAGES IN GENERAL DEVELOPMENT PROCESS OF AUTOMOBILE PRODUCTS

\section{B. Quality Control of Automobile Product Project}

The current automobile product project early quality management intervention as shown in Figure III below:

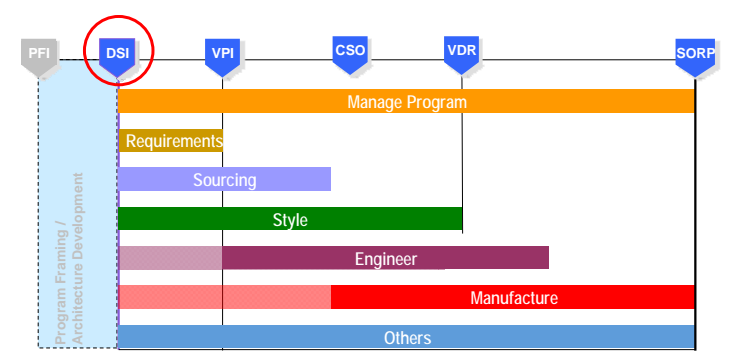

FIGURE III. QUALITY CONTROL OF ANTOMOBILE PRODUCT PROJECT

From Figure III, we can see that the existing project quality management participation is from the VDR (Verified Data Release) node, that is, the design phase of the design to intervene. At this point, the development of the project structure has been basically finalized. The existing development process required in the VDR phase, the project quality management manager will product quality requirements and customer complaints case input to the project. In the follow-up project list, the project developer feedback on the input problem, and in the corresponding project quality valve for review.

But in fact, due to the early stage of the project structure has been finalized, related to the promotion of the structure of the problem, there is still a large resistance. Moreover, engineering personnel and project quality management personnel in the technical master is not equal, project quality personnel to assess the project developers on the issue of prevention of state feedback, there may be a certain gap. Therefore, there is a lack of assessment of the prevention program for some input problems, resulting in the risk from the project to the market. 


\section{THE SUMMARY AND OF THE EXISTING WARRANTY QUALITY IMPROVEMENT AND PROJECT QUALITY CONTROL}

There are some deficiencies in the existing process of warranty quality improvement and project quality control:

1) Existing automotive warranty quality improvement is more concerned about the problem itself, from the problem found to solve the problem, presenting an open design, is a passive response process, has not formed a real PDCA quality closed-loop management.

2) At present, the quality control of the automobile project is involved in the late stage of the vehicle structure, and the quality of the project prevention program and risk assessment system is limited by the technical knowledge level of project quality management personnel. Therefore, the project quality control has a certain lag and limitations.

3) The warranty quality improvement and project quality control of the array, they lack effective communication. On the one hand, the quality of customer service is faced with all kinds of quality improvement from the market demand; on the other hand, the project quality management personnel technical level limit, input and evaluation of project quality can not fully guarantee the effective prevention of customer service and quality problems not to repeat.

\section{WARRANTY QUALITY IMPROVEMENT AND PROJECT QUALITY PREVENTION CONTROL OPTIMIZATION}

In order to continuously improve the existing problems, in order to better adapt to the continuous development of the market for automotive product quality requirements. For each of the above developed a corresponding optimization:

1) Through summing up the experience of the past warranty quality problems, the establishment of after sale failure mode library, and constantly add new cases, dynamic update the knowledge base. At the same time, as the carrier of this knowledge base, the formation of real PDCA closed loop management. Namely from the discovery problem, to solve the problem, to the input problem, to the project prevention, as shown in Figure IV.

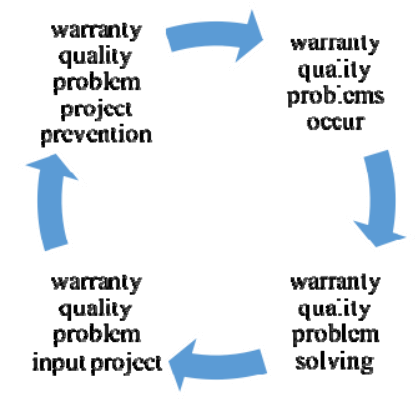

FIGURE IV. REAL PDCA CLOSED LOOP MANAGEMENT

2) Improve the project quality control process, start the quality management work in the early stage of the whole vehicle project, and input the quality requirements into the architecture development phase of the project.
At the same time, for the project quality prevention programs, the establishment of expert evaluation mechanism, reduce the project management personnel technical level constraints, resulting in the project quality issues into warranty.

3) Establish the communication platform between the warranty quality and project quality. The failure mode library is the carrier to form the quality problem solving and sharing mechanism. Through regular communication, so that warranty quality problems, timely and accurate import project quality.

At the same time, the quality of the project to prevent the state, timely feedback to the quality of service to confirm and assess. Really change the situation of warranty quality and project quality for their own, improving the effectiveness of warranty quality improvement, and enhancing the quality of the project to assess the ability to prevent the problem.

\section{METHODS AND TOOLS FOR THE ANALYSIS AND SOLUTION OF WARRANTY QUALITY PROBLEMS}

A. The Application of 7D in the Analysis of Quality Problems

7D is mainly to help the use of the right idea to find the cause of the problem, its compliance with the principle of easy to difficult, based on the establishment of statistical data. According to experience, most of the quality problems, the reasons are in the first 4 diamonds, the proportion of no accurate statistics, estimated at between $60 \%$ to $90 \%$, different projects will have a different situation.

Question 1): is it all the quality issues that need to be analyzed using 7D?

$7 \mathrm{D}$ as a process, its purpose is to help quickly find the cause of the problem, reduce or avoid detours, but not the golden laws and precious rules also has its limitations.

Therefore, for an experienced engineer, combined with their own experience, to carry out a comprehensive careful observation, the use of flexible methods, the use of a tool to be more effective than rigid.

\section{B. The Application of X Red in Warranty Quality Analysis}

Red $X$, is a tool to find the root of the problem in the differences. X represents the underlying cause of the unknown, and Red represents the greatest impact. Through the exchange of BOB/WOW test and other methods, to identify potential reasons and to verify the identification, given Pink X, Red X and other factors, so as to impose targeted measures to solve. Its foundation is also statistics, its application is generally quite complex, can not find the cause of the problem by conventional means.

\section{Question 1): is the project stage Red X often used?}

Due to the urgency of the project, as well as a small number of early vehicle project, the sample is scarce, it is difficult to find a suitable WOW $\mathrm{BOB}$ / and other reasons, this case is less used Red X. 
Red X requires considerable human input, and usually a Red X project from start to finish often requires a few months or even six months time, the requirements are relatively high, and the project stage is difficult to support such requirements.

\section{Application of a Single Issue List}

SIL- Single Issue List. The list is used to unify the various relative important quality issues found in the relevant area after the sale. These issues are aggregated to SIL, by hand for maintenance and tracking, the promotion of the problem by a special meeting, and set the quality valve, the state of the company's management to audit the status of these issues.

This list is similar to the current production of the CPIP list and TOP problem list, but the difference is the number of SIL in the problem, the solution time is short, the work intensity.

\section{PRTS + Tool Application}

PRTS+ is to solve the problem by GM and tracking system, similar to SIL, but its use is the network database, authorized person can login to view and update for problem solving, so popular with GM engineers. SAIC GM is also now being asked to use the system immediately to promote the GLOBAL project, such as E2XX, D2XX and other items of the quality of the problem to get a quick response and resolve.

Due to the PRTS+ server is located in North America, the SAIC GM, view and slow operating speed, a long time, so had been reluctant to use the system. But from the project E2XX, the global platform projects accounted for the vast majority of all GM projects, general motors and other regional exchanges became frequent, because of the style, habits and ways of thinking are different, only use the SIL caused by the contradiction has become increasingly prominent, SAIC GM needs to change.

\section{THE EXPECTED RESULTS OF WARRANTY QUALITY IMPROVEMENT AND PROJECT QUALITY CONTROL METHOD TO OPTIMIZE}

Through the systematic optimization of the warranty and project quality management, in accordance with the quality of PDCA management concept, which can basically cover the problem (Plan), problem solving (Do), assessment (Check), prevention (Action) the quality of the product whole life cycle improvement requirementsAt the same time, through the establishment of the corresponding quality sharing and exchange platform, to further strengthen the prevention and assessment of project issues, to avoid the problem of flow to the warranty.

According to the system forecast, after the implementation of the warranty and project quality management system optimization, to achieve effective prevention of project quality issues into the warranty, the warranty quality complaints are expected to be reduced by $26 \%$.

Overall, reduce work pressure to solve the warranty quality, enhance project quality control ability, improve customer service satisfaction the win-win situation.

\section{CONCLUSION}

This article through to the existing warranty quality problem solving and project quality management status analysis, and combined with many years warranty quality work experience and experience. Focus on the quality of closed loop management perspective and to strengthen the quality of prevention, this paper gives the quality optimization program of the warranty quality problem solving and project management. Effectively supplement the existing warranty quality and project quality management ideas and methods.

\section{ACKNOWLEDGEMENT}

The authors gratefully acknowledge the financial support of the innovation practice program of Shanghai (IPP13036), and the national natural science foundation, China (No. 51435009)

\section{REFERENCES}

[1] DAVID JB,LYNNE R,The Relationship Between Total Quality Management and the Focus of Project Management Practices [J],The TQ M Magazine,2007, 19(1),50-61.

[2] PMI Standard Committee, Project Management Book, PMI, 2000.

[3] Project Management Institute. A Guide to the Project Management Body of Knowledge [M], USA: Project Management Institute, 2000:236-241.

[4] SHIEH H M, WU K Y. The Relationship between Total Quality Management and Project Performance in Building Planning Phase: an Empirical Study of Real Estate Industries in Taiwan [J] Total Quality Management, 2002, 13(1):133-151 